\title{
Review on Application of Agro-Waste Biomass Biochar for Adsorption and Bioremediation Dye
}

\author{
BS Giri*, Mandavi Goswami and RS Singh \\ Chemical Engineering and Technology, Indian Institute of Technology, Varanasi 221005, India
}

Received: December 05, 2017; Published: December 12, 2017

*Corresponding author: Balendu Shekher Giri, Chemical Engineering and Technology, Indian Institute of Technology, Varanasi 221005, India; Email: balendushekher23@gmail.com

\begin{abstract}
This review brings the little knowledge about the effectiveness of combined bio-film and biochar approach in bio-sorption method for the removal of synthetic dye which generated from wastewater of textile and carpet industries. Removal studies of dye through packed bed bioreactor performed with immobilized bacteria on agro waste biomass and biochar (i.e., biofilms on biochar). This review suggests the combined approach may be a likely factor of treatment of dye effluents. Several models including Langmuir isotherm and Freundlich are useful to studies of sorption of dye on to biochar prepared by agro waste.
\end{abstract}

Keywords: Biochar; Sorption; Bioreactor; Mixed Culture; Langmuir isotherm model

\section{Introduction}

Biomass-based fuels dominated the world energy market until the middle of the $19^{\text {th }}$ century, when coal and other fossil fuels become increasingly popular. Since the $20^{\text {th }}$ century, just over 100 years, mass production and utilization of fossil energy have caused a series of worldwide energy supply and global environmental and climate problems. Hence the use of sustainable energy sources has been attracting research attention over the last several decades. Compared to the use of other sustainable fuel resources, biomass has the advantage of wide availability and it can be developed everywhere in the world as a local fuel resource. Due to a rapid increase of global population and the fast development of urbanization, about 1 billion metric tons of organic solid wastes are annually generated from world cities, causing great challenges on the management of these wastes Lim, 2016. The major negative effect of burning agricultural wastes is the release of carbon dioxide gas (CO2), which is the most important factor of greenhouse gas production by the human. Carbonization of woody or cellulosic wastes to produce biochar which is a charcoal-like product. It has been suggested by several researchers to avoid negative impacts of the direct burning of woody matter. Biochar is resistant to biological decay and hence preserved in the terrestrial systems for the much longer time. For example, woody residues or compost, therefore, the beneficial effects are extend $[1,2]$.

Carbonization through pyrolysis is to produce biochar is a successful mean to avoid the negative impacts on human health and environment. Biochar is the black solid containing recalcitrant organic carbon (OC), which helps in global warming mitigation [3]. Recently, attention has been paid to the utilization and application of biochar, which is derived from the biomass via incomplete combustion operations such as pyrolysis and carbonization [4,5]. Pyrolysis could be considered one of the fastest ways for depolymerization of biomass macromolecules to smaller molecular fragments. As a stable carbon-rich material, the application of biochar for solving environmental problems can span several categories including: carbon sequestration, soil management, pollution remediation, and agricultural by-product/ waste recycling. Among these uses, biochar as an adsorbent for the removal of environmental pollutants has emerged as a promising technology [6]. Currently, low-temperature pyrolysis is usually applied to convert biomass, typically agricultural biomass, into biochar [7], which helps to avoid organic leaching and secondary pollution from the raw biomass. Meanwhile, the surface area of the biochar usually increases with an increase in pyrolytic temperature at up to $700 \mathrm{oF}[4]$.

As such, it was deemed both reasonable, and feasible, to promote the application of biochar for practical decontamination purposes. The residual dyes in the effluent stream from different sources (e.g., textile industries, paper and pulp industries, dye and dye intermediates industries, pharmaceutical industries, tannery, and Kraft bleaching industries, etc.) contains wide variety of organic pollutants is one of the important source of water pollution, ecological problems and health effects of all over the 
world [8]. The presence of lowest concentrations of dyes in the effluent is highly visible and undesirable in the environment. The effluent also contains the residues of reactive dyes and harmful chemicals. Therefore, such type of wastewater needs to be properly treated before release into the environment. There are several decolorization techniques is reported in which physical, chemical, and biological decolorization technologies available. The physical sorption technique is a most effective and attractive process for the decolorization of dye-containing wastewater [9]. In general, adsorption processes are using a commercial activated carbon which is effective for the decolorization of dyes from contaminated wastewater. The consumption of activated carbon is steadily increasing because of its application in pollution control in the word $[10,11]$. Adsorption has been considered to be one of the most effective physical techniques for removing contaminants from water because using adsorption methods is inexpensive and easy to manage [12]. Biochar is a carbon-rich product which is produced by combusting biomass, such as wood, manure, wheat straw, wicker, sewage sludge, or leaves, at between 350 and 7000C $[13,14]$ in a closed chamber with insufficient air or no air. Biochar is currently being used in a number of fields, including energy production, waste management, climate change mitigation, water treatment, and soil amelioration [4]. 2 Using biochar as an adsorbent has been found to offer great potential for removing organic contaminants from water [15]. Recently, works have been done on the methylene blue adsorption by biochar. Delwiche, 2014 showed that the use of $1 \mathrm{~kg} / \mathrm{m} 2$ pine chip biochar could decrease the leaching of methylene blue from a homogenized soil column by $52 \%$ [16]. Found that the adsorption of methylene blue on Biochar of Casuarina seeds involved the mechanism of the weak H-bond with hydroxyl groups and also concluded that $\mathrm{p}$-p electron donoracceptor and steric effects play important roles in adsorption. [17] Revealed that the biochar prepared from agro wastes when added into soil could increase the sorption of Casuarina seeds; however, the reaction mechanism relating to the soil characteristics was not well interpreted. Biochar from different sources have different properties and different adsorption characteristics. The mechanism of adsorption was examined by characterizing biochar prepared from Casuarina seeds agro wastes. The choice of these feed stocks depended on the availability and ease of access in India [18]. The feed stocks were selected with the aim of utilizing droppings and vegetable wastes produced in agricultural areas. The physicochemical properties of these biochar were systemically characterized in relating to their adsorption behavior. The effects of key parameters (initial methylene blue concentration, temperature, and $\mathrm{pH}$ ) on the adsorptive removal of methylene blue by the biochar mentioned above were evaluated using batch experiments and compared. Although a number of low-cost adsorbents such as: natural materials, agricultural, and industrial, wastes are capable of removing methylene blue efficiently [19-21].

\section{Acknowledgement}

The authors are thankful for Department of Chemical Engineering and Technology, IIT (BHU), Varanasi for his valuable guidance through the experiments. Authors also acknowledge Project Varanasi for the financial support.

\section{References}

1. Lehmann J (2007) A handful of carbon. Nature 447(7141): 143-144.

2. Lehmann J, Joseph S (2009) Biochar for Environmental Management: Science and Technology. Earthscan, London \& Sterling, London, UK.

3. Lehman J, Rillig MC, Thies J, Masiello CA, Hockaday WC, et al. (2011) Biochar effects on soil biota-a review. Soil BiolBiochem 43: 1812-1836.

4. Ahmad M, Rajapaksha AU, Lim JE, Zhang M, Bolan N, et al. 2014. Biochar as a sorbent for contaminant management in soil and water: a review. Chemosphere 99: 19-33.

5. Mohan D, Sarswat A, Ok YS, Pittman Jr, Charles U (2014) Organic and inorganic contaminants removal from water with biochar, a renewable, low cost and sustainable adsorbent-a critical review. Bioresour. Technol 160: 191-202.

6. Zhou Y, Gao B, Zimmerman AR, Chen H, Zhang M, et al (2014) Biocharsupportedzerovalent iron for removal of various contaminants from aqueous solutions. Bioresour. Technol 152: 538-542.

7. Das L, Kolar P, Classen JJ, Osborne JA (2013) Adsorbents from pine wood via K2CO3-assisted low temperature carbonization for adsorption of p-cresol. Ind Crops Prod 45: 215.

8. Robinson T, McMullan G, Marchant, Nigam P (2001) Remediation of dyes in textile efMluent: a critical review on current treatment technologies with a proposed alternative. Bioresour Technol 77(3): 247-255.

9. Aksu Z, Tezer S (2005) Biosorption of reactive dyes on the green alga Chlorella vulgaris. Process Biochem 40(3): 1347-1361.

10. Yuan JH, Xu RK, Zhang H (2011) The forms of alkalis in the biochar produced from crop residues at different temperatures. Bioresour Technol 102: 3488-3497.

11. Yuan XZ, Shi XS, Zeng J, Wei YL (2011) Activated carbons prepared from biogas residue: characterization and methylene blue adsorption capacity. J Chem Technol Biotechnol 86: 361-366.

12. Weng CH, Lin YT, Tzeng TW (2014) Removal of methylene blue from aqueous solution by adsorption onto pineapple leaf powder. J Hazard Mater 170: 417- 424 .

13. Wang H, Gao B, Wang S, Fang J, Xue Y, Yang K (2015) Removal of Pb(II), $\mathrm{Cu}(\mathrm{II})$, and $\mathrm{Cd}(\mathrm{II})$ from aqueous solutions by biochar derived from KMnO4 treated hickory wood. Bioresour Technol 197: 356-362.

14. Wang M, Sheng G, Qiu Y (2015) A novel manganese-oxide/biochar composite for efMicient removal of lead(II) from aqueous solutions. Int J Environ Sci Technol 12(5): 1719-1726.

15. Wu CH, Chang SH, Lin CW (2015) Improvement of oxygen release from calcium peroxide- polyvinyl alcohol beads by adding low-cost bamboo biochar and its application in bioremediation. Clean - Soil Air Water 43: 287-295.

16. Zhang MM, Liu YG, Li TT, Xu WH, Zheng BH (2015) Chitosan modification of magnetic biochar produced from Eichhorniacrassipes for enhanced sorption of $\mathrm{Cr}(\mathrm{VI})$ from aqueous solution. RSC Adv 5(58): 46955-46964.

17. Deng D, Yu H, Chen M, Ge C (2014) Sorption of atrazine by biochar prepared from manioc wastes in tropical soils. Adv Mater Res 878: 433442.

18. Inyang MD, Gao B, Yao Y, Xue YW, Zimmerman, et al. (2012) Removal of heavy metals from aqueous solution by biochars derived from anaerobically digested biomass. Bioresour Technol 110: 50-56.

19. Rafatullah M, Sulaiman O, Hashim R, Ahmad A (2010) Adsorption of methylene blue on low-cost adsorbents: a review. J Hazard Mater 177: 70-80.

20. Vikash Bharti, Shahi A, Geed SR, BS Giri, RS Singh, et al. (2017) Biodegradation of Reactive Orange 16 dye in packed bed bioreactor using ashoka and Casuarina Seeds as a packing media. Indian journal of Biotechnol 16(2). 


- Assets of Publishing with us
- Ilobal archiving of articles

